\title{
Differential expression and function of $A R$ isoforms in prostate cancer
}

\author{
RUI ZENG* ${ }^{*}$ ZHIYONG LIU*, YINGHAO SUN and CHUANLIANG XU \\ Department of Urology, Changhai Hospital, Second Military Medical University, Shanghai 200433, P.R. China
}

Received October 8, 2011; Accepted October 20, 2011

DOI: $10.3892 /$ or.2011.1516

\begin{abstract}
The androgen receptor (AR) plays a key role in prostate cancer (PCa). Two isoforms of AR, are AR-A and -B, which differ by a lack of the first 187 amino acids in the NH2-terminal transactivation domain of AR-A. Since little is known about the expression and basic function of the AR$\mathrm{A} / \mathrm{B}$ isoforms in prostate cancer, the aim of this study was to analyze this possible association. The AR-A, -B and AR-A/B ratio was determined in the tissues of healthy controls, benign prostate hyperplasia (BPH) and $\mathrm{PCa}$ by means of Western blot analysis and immunofluorescence. The elevation of AR$\mathrm{A}$, and $-\mathrm{B}$, as well as the $\mathrm{AR}-\mathrm{A} / \mathrm{B}$ ratio with regard to Gleason scores, were assessed in prostate cancer compared to $\mathrm{BPH}$ and normal prostate. In order to further investigate the role of AR A/B isoform function, we transfected PC3 cells with an AR or AR-A expression vector. The overexpression of AR-A and $-\mathrm{B}$ significantly decreased the invasion and proliferation of PC3 cells. However, the overexpression of AR-A further decreased proliferation but accelerated the invasion of $\mathrm{PC} 3$ cells compared to AR-B. In conclusion, the elevation of AR$\mathrm{A}$ and $-\mathrm{B}$, and the $\mathrm{AR}-\mathrm{A} / \mathrm{B}$ ratio, is associated with prostate cancer occurrence and progression. Furthermore, AR-A could provide a new potential therapy with regard to the decrease in the invasion and proliferation of prostate cancer cells. Our study provides insight into further understanding the biological role of AR-A in its interaction with AR-B and its impact on PCa clinical treatment.
\end{abstract}

\section{Introduction}

Androgens play a crucial role in gender differentiation, development, and in the expression of the male phenotype (1). Androgens exert their biological effects through their

Correspondence to: Dr Yinghao Sun, Department of Urology, Changhai Hospital, Second Military Medical University, Shanghai 200433, P.R. China

E-mail: sunyinghao516@gmail.com

${ }^{*}$ Contributed equally

Key words: prostate cancer, androgen receptor, protein isoforms binding to the androgen receptor (AR). AR is implicated in prostate cancer progress and treatment in addition to its role in normal prostate development and function. AR is a member of the nuclear receptor superfamily which includes the thyroid, estrogen, progesterone, and the glucocorticoid and mineralocorticoid receptors (2). Most of the members' genes encode more than 1 isoform protein as a consequence of either alternative promoter utilization or alternative mRNA splicing. Unexceptionally, the 2 isoforms of AR, AR-A and $-\mathrm{B}$, which are identical except that the shorter AR-A protein is N-terminally truncated by 187 amino acids compared to the traditional full-length AR-B, were first determined in 1994 (Fig. 1) (3). Wilson and McPhaul suggested that AR-A is produced by the initiation of protein synthesis at the internal Met-188 residue of AR-B (3). Within the nuclear receptor superfamily, the 2 isoforms of $A R$, bear the most striking similarity to the progesterone receptor (PR), as a single gene gives rise to 2 distinct isoforms which differ in the N-terminal amino acid domain. In the case of PR, PR-A and $-\mathrm{B}$ differ in their transgenic functions as has been previously reported (4-7). There have also been reports that the high expression of PR-A is related to human breast cancer (8). Till now, studies have mainly been focused on the PR isoforms, and not on the AR ones. Catalano, et al discovered that neoplastic colon tissue shows a characteristic loss of expression of the AR-B isoform, while the AR-A expression remains unaltered, compared to healthy colon mucosae (9). The AR isoforms, AR-A and -B, display functional differences in cultured human bone cells and genital skin fibroblasts (10). Guo, et al identified a new AR splice variant lacking the $\mathrm{C}$-terminal ligand-binding domain in hormone-insensitive PCa cells, which is constitutively active, and its transcriptional activity is not regulated by androgens or anti-androgens (11). Further analysis has also shown that the new AR variant is correlated with tumor recurrence.

Prostate cancer $(\mathrm{PCa})$ is the most common malignancy in men, and the second most common cause of cancer death in America (12). Given the different transcriptional activities of the $\mathrm{AR}$ isoforms, the analysis of the AR-A and -B expression in normal prostate and its pathological lesions, as well as the analysis of their different functions, is crucial to understanding their respective roles in these tissues (10).

We performed the present study in order to elucidate the $\mathrm{AR}$ isoform expression and its basic activities in prostate cancer. 


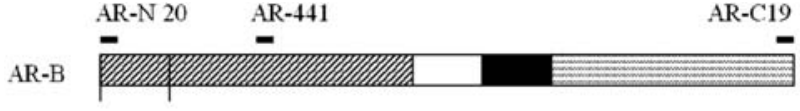

Met1 Met188

AR-A

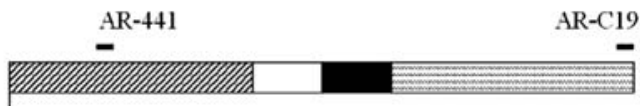

Figure 1. AR isoform proteins AR-A and -B and 3 different AR antibodies.

\section{Materials and methods}

Subjects. Tissue samples of 15 normal prostate served as the controls. Additionally, tissue samples of 15 patients with a diagnosis of benign prostate hyperplasia (BPH) and 50 patients with a pathological diagnosis of $\mathrm{PCa}$, were obtained from the Department of Urology at Changhai Hospital. The stages of PCa were assigned in accordance to the AJCC guidelines (13). All the clinical parameters of the patients were collected by trained personnel. The tissues were immediately frozen in liquid nitrogen until measurement. The ages of the PCa group were between 51 and 88, and the average age was $69 \pm 74$ years. The PCa group was divided into 2 subgroups according to clinical stage, whereby 46 patients were classified as stage $\leq \mathrm{T} 2,4$ as stage $>\mathrm{T} 2$, or by the Gleason score, whereby 40 patients were classified as Gleason $\leq 7$, and 10 as Gleason $>7$. The study protocol was approved by the Ethics Committees of the hospital.

Western blotting. Western blotting was performed as follows: Briefly, the tissues were prepared in RIPA buffer containing protease inhibitors. The proteins were determined by the BCA protein assay kit (Pierce, Rockford, USA). Equal protein amounts were separated by $10 \%$ SDS-PAGE and transferred to nitrocellulose membranes (Bio-Rad). After blocking in 5\% non-fat dry milk in Tris-buffered saline, $\mathrm{pH} 7.6$, with $0.1 \%$ Tween-20 (TBS-T buffer), for $1 \mathrm{~h}$ at room temperature, the membranes were incubated with the primary antibody [1:200 in TBS-T; either AR mouse monoclonal antibody (SC-7305) raised against amino acids $299-315$ of the AR protein, or AR $\mathrm{N}-20$ binding to the NH2-terminus, or AR C-19 binding to the C-terminus; Santa Cruz], followed by thorough rinsing in TBS-T and treatment with the secondary peroxidase-linked antibody (1:2000). The detection of AR was performed with enhanced chemiluminescence reaction and exposure to X-ray film. To ensure the equality of protein loading, the same membrane blots were stripped off and re-probed with an antiGAPDH antibody. Gray-scale measurements of AR-A/B were performed with Image-Pro software.

Dual immunofluorescent staining and fluorescence analysis. The tissues were fixed in paraffin, cut into $4-\mu \mathrm{m}$ sections and mounted onto polylysine-coated slides. After deparaffinization, the slides were transferred into $1 \mathrm{mM}$ EDTA $\mathrm{pH} 8.0$ in a microwave oven for $15 \mathrm{~min}$ for antigen retrieval. Following antigen retrieval, the sections were stained with primary antibody. As AR-A bears the identical sequence of AR-B, an antibody that recognizes AR-A only is not acquirable. Consequently, in order to reveal the expression of

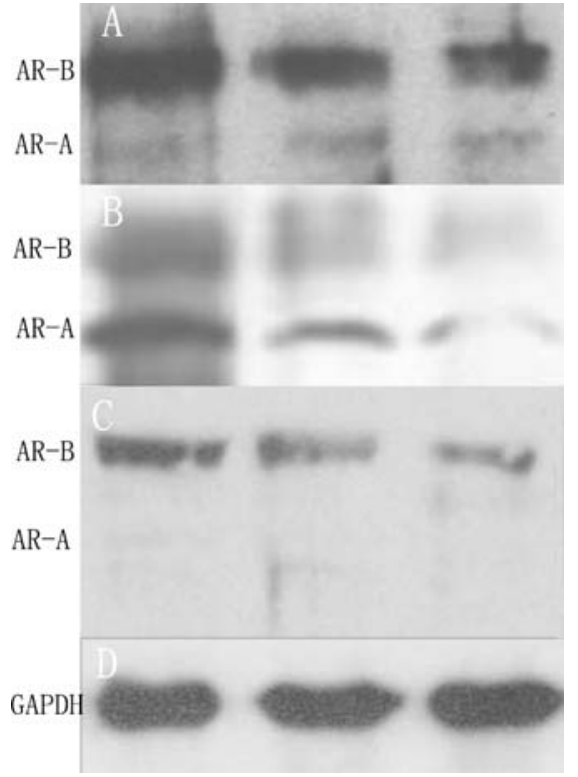

Figure 2. The differential expression of AR-A/B in different prostate tissues. (A) The AR protein band was visualized as a group of 2 migrating bands by the antibody AR SC-7305 raised against amino acids 299-315 of the AR-B protein. (B) The AR protein band was visualized as a group of 2 migrating bands by the antibody AR C-19 binding to the C-terminus of the AR protein. (C) AR-A was not detectable using the antibody AR N-20 directed against the NH2-terminus of the AR-B protein. (D) GAPDH

AR-A/B, we used the SC-7305, to detect AR-A and AR-B and the rabbit polyclonal antibody (SC-816), to detect AR-B only. The primary antibodies at a concentration of $1: 100$ were incubated overnight at $4{ }^{\circ} \mathrm{C}$. Cy3-goat-anti-mouse secondary antibody (Dako) and FITC-goat-anti-rabbit secondary antibody (Dako) were incubated for $30 \mathrm{~min}$ at $37^{\circ} \mathrm{C}$. The sections were mounted and stored in the dark at $4^{\circ} \mathrm{C}$. AR staining was examined by the Olympus BX 40 fluorescence microscope equipped with filters to detect $\mathrm{Cy} 3$ and FITC fluorescence separately, and the intensity per field was recorded. The relative expression of AR-A and -B was assessed by determining the level of the FITC and CY3 fluorescence in 100 prostate epithelial cells. Image-Pro software was used to determinate the relative expression levels of the FITC and CY3 fluorescence.

Transfection vectors, cell culture and Western blot analysis of AR isoforms in PC3 cells. A human full-length AR expression plasmid with pEGFP-AR-B as the parent vector, was preserved in our laboratory. In order to obtain a vector expressing the truncated sequence of AR (corresponding to AR-A), pEGFP-AR-B was digested with NheI and SmaI (Fermentas). 5-end 188 codons were truncated and the vector was religated with T4 DNA ligase to form pEGFP-AR-A. The PC3 cells were cultured in RPMI-1640 medium supplemented with $10 \% \mathrm{v} / \mathrm{v}$ fetal calf serum at $37^{\circ} \mathrm{C}$ in a humidified atmosphere of $5 \% \mathrm{CO}_{2}$ in air (14), and passed every 5 days using trypsin/EDTA. The PC3 cells were grown in 6 -well plates to a confluence of $\sim 70-80 \%$. Transfection was performed with a $4 \mu \mathrm{g}$ plasmid and $10 \mu \mathrm{l}$ Lipofectin ${ }^{\circledR}$ reagent (Gibco) per well in a total volume of $500 \mu \mathrm{l}$ OptiMEMI (Gibco) according to the manufacturer's instructions. 


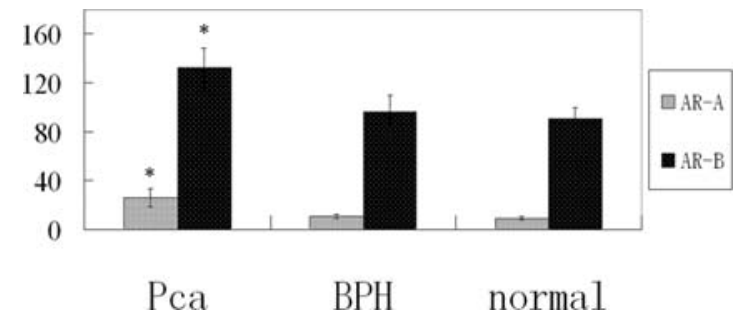

Figure 3. The expression of AR-A increased 2.38-2.81-fold and that of AR$\mathrm{B}$ increased 1.37-1.47-fold in PCa compared to the normal prostate tissues and $\mathrm{BPH} .{ }^{*} \mathrm{P}<0.05$ compared to normal prostate.

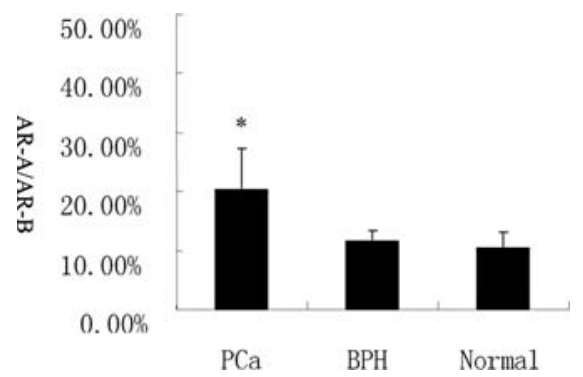

Figure 4. The ratio of AR-A/B in PCa increased 1.75-1.92-fold compared to the normal prostate tissues and $\mathrm{BPH}$. ${ }^{*} \mathrm{P}<0.05$ compared to normal prostate.

The medium was changed to RPMI-1640 and 10\% FCS $4 \mathrm{~h}$ later. Cellular extracts were prepared by lysis and scraped off the dish $48 \mathrm{~h}$ later from the transfection. Cellular protein was determined by the BCA protein assay kit (Pierce). The samples were denatured and mixed 1:5 with protein loading buffer. The Western blot was performed as described above.

Effect of AR isoforms on cell proliferation and migration assay. AR-defective $\mathrm{PC} 3$ cells were transfected with the AR expression vectors, $\mathrm{pEGFP-AR-B}$ or $\mathrm{pEGFP-AR-A}$, and cell proliferation mediated by the AR isoforms, were investigated. Then cell proliferation was assayed by using a Cell Counting Kit-8 (Dojindo) according to the manufacturer's instructions. Each group was assigned to 3 parallel wells. The control plasmid pEGFP was also transfected as the control.

Cell migration was assayed by the in vitro $8.0-\mu \mathrm{m}$-poresize Matrigel coated transwell (Costar). The 24-well plate was prepared by adding $0.5 \mathrm{ml}$ RPMI-1640 and 10\% FCS. An insert was placed into each prepared well with the membrane toward the well bottom. The cell suspension (2000 cells in $200 \mu \mathrm{l}$ RPMI-1640 and $2 \%$ FCS) was added to the interior of each insert. Cells were allowed to migrate for $72 \mathrm{~h}$ and were then stained with $1 \%$ methylrosanilinium chloride. Nuclei from the migrated cells were counted in 8 different random fields from each sample and the averages were calculated. Each data point represented the averages from 3 individual experiments. The controls were chambers with PC3 cells.

Statistical analysis. Statistical analysis was performed by parametric methods (t-test or ANOVA), using the SPSS V10.0 microcomputer programs. A P-value of $<0.05$ was considered statistically significant.
Table I. Association of AR isoforms and Gleason score variables by Western blot analysis.

\begin{tabular}{lccc}
\hline & $\begin{array}{c}\text { Gleason } \\
\text { score } \leq 7\end{array}$ & $\begin{array}{c}\text { Gleason } \\
\text { score }>7\end{array}$ & P-value \\
\hline Patient age & $69.36 \pm 7.11$ & $69.50 \pm 7.99$ & 0.940 \\
PSA & $21.42 \pm 21.37$ & $29.97 \pm 15.81$ & 0.240 \\
AR-A & $25.20 \pm 7.13$ & $31.15 \pm 5.27$ & 0.019 \\
AR-B & $128.61 \pm 14.80$ & $147.51 \pm 12.75$ & 0.001 \\
AR-A/AR-B & $0.20 \pm 0.06$ & $0.21 \pm 0.04$ & 0.468 \\
\hline
\end{tabular}

Table II. Association of AR isoforms and clinical stage variables by Western blot analysis.

\begin{tabular}{lccc}
\hline & $\begin{array}{c}\text { Clinical } \\
\text { stage } \leq \mathrm{T} 2\end{array}$ & $\begin{array}{c}\text { Clinical } \\
\text { stage }>\mathrm{T} 2\end{array}$ & P-value \\
\hline Patient age & $69.07 \pm 7.91$ & $65.75 \pm 12.93$ & 0.315 \\
PSA & $24.63 \pm 22.78$ & $45.37 \pm 34.61$ & 0.024 \\
AR-A & $26.56 \pm 7.13$ & $28.62 \pm 5.71$ & 0.528 \\
AR-B & $133.13 \pm 16.09$ & $142.49 \pm 9.42$ & 0.203 \\
AR-A/AR-B & $0.20 \pm 0.06$ & $0.20 \pm 0.04$ & 0.981 \\
\hline
\end{tabular}

\section{Results}

Distribution of AR isoforms in different human prostate tissues. The AR protein band was visualized as a group of 2 migrating bands (Fig. 2). This was consistent with previous observations in other tissues (15). Western blot analysis of the crude protein extracts revealed that AR-A and -B were present at low levels. AR-A and -B was also detected using an antibody directed against the C-terminus (Fig. 2B). AR-A was not detectable using an antibody directed against the NH2-terminus of AR-B (Fig. 2C).

There were no differences in the expression of AR-A and $-\mathrm{B}$, and in the ratio of $\mathrm{AR}-\mathrm{A} / \mathrm{B}$ between normal prostate tissues and $\mathrm{BPH}$ (AR-A $\mathrm{P}=0.703$, AR-B P=0.505, AR-A/AR$B$ ratio $P=0.871)$. However, the expression of $A R-A$ and $-B$, and the ratio of $\mathrm{AR}-\mathrm{A} / \mathrm{B}$ in $\mathrm{PCa}$, were much higher than in the normal prostate tissues and $\mathrm{BPH}$ (AR-A comparison $\mathrm{P}<0.01$, AR-B comparison $\mathrm{P}<0.01$ and $\mathrm{AR}-\mathrm{A} / \mathrm{B}$ comparison $\mathrm{P}<0.01$, ANOVA). The AR-A expression in $\mathrm{PCa}$ was increased by 2.38-2.81 times compared to $\mathrm{BPH}$ and normal prostate. The expression of AR-B in PCa increased 1.371.47-fold (Fig. 3). Thus, the AR-A/B ratio increased 1.751.92-fold (Fig. 4). A multiple range test showed that the AR-A and AR-B levels of the Gleason $>7$ group were significantly higher than those of the Gleason $\leq 7$ group. However, the patient age $(\mathrm{P}=0.94)$, PSA $(\mathrm{P}=0.24)$ and the ratio of the AR-A/B levels $(\mathrm{P}=0.468)$ of the Gleason $\leq 7$ and Gleason $>7$ group patients, were not significantly different from one another (Table I). The difference between AR-A and $-\mathrm{B}$, and the AR-A/B ratio between stages $\leq \mathrm{T} 2$ and $>\mathrm{T} 2$, were not statistically significant, which could be due to the inadequate tissues in the stage $>\mathrm{T} 2$ group (Table II). 

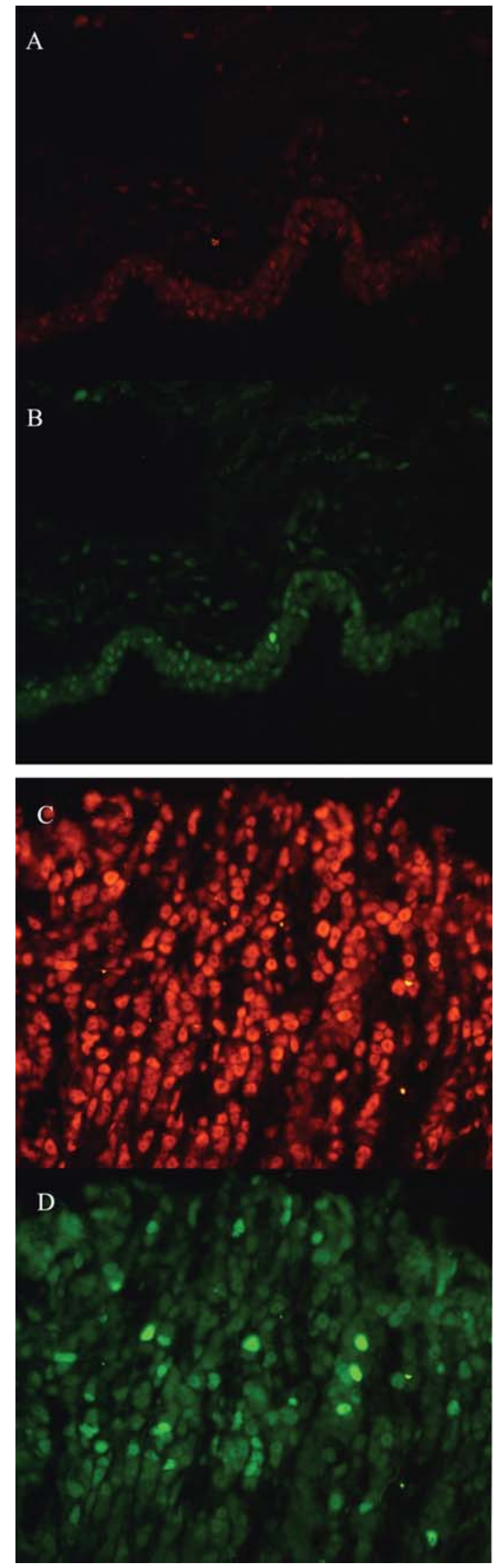

Figure 5. The increased AR isoform expression in PCA cells by dual immunofluorescent staining in compared to normal prostate and BPH. Different human prostate tissues were stained with SC-7305 to detect AR-A and -B and SC-816 to detect AR-B only. Red fluorescence excited from $\mathrm{Cy} 3$ represented $A R-A$ and $-B$, and green fluorescence from FITC represented AR-B only. (A) AR-A and -B expression in normal prostate tissues. (B) AR-B expression in normal prostate tissues. (C) AR-A and -B expression in PCa. (D) AR-B expression in PCa.

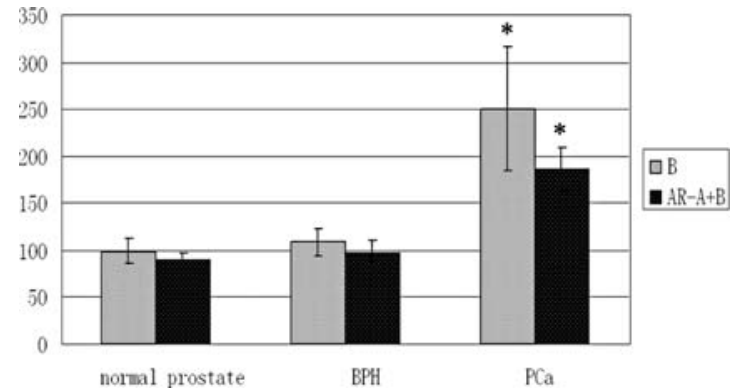

Figure 6. Red fluorescence increase in PCa tissues 2.10 and 1.93 times in contrast to the normal prostate tissue and $\mathrm{BPH}$. Green fluorescence in $\mathrm{PCa}$ tissues increased 2.53 and 2.31-fold in contrast to the normal prostate tissue and $\mathrm{BPH} .{ }^{*} \mathrm{P}<0.05$ compared to normal prostate.

Table III. Association of AR isoforms and Gleason score variables by dual immunofluorescent staining.

\begin{tabular}{lccc}
\hline & $\begin{array}{c}\text { Gleason } \\
\text { score } \leq 7\end{array}$ & $\begin{array}{c}\text { Gleason } \\
\text { score }>7\end{array}$ & P-value \\
\hline Patient age & $69.36 \pm 7.11$ & $69.50 \pm 7.99$ & 0.940 \\
PSA & $21.42 \pm 21.37$ & $29.97 \pm 15.81$ & 0.240 \\
AR-B & $232.06 \pm 56.09$ & $323.06 \pm 45.06$ & 0.080 \\
AR-A+B & $180.79 \pm 22.26$ & $202.80 \pm 16.30$ & 0.003 \\
\hline
\end{tabular}

Table IV. Association of AR isoforms and clinical stage variables by dual immunofluorescent staining.

\begin{tabular}{lcrc}
\hline & $\begin{array}{c}\text { Clinical } \\
\text { stage } \leq \mathrm{T} 2\end{array}$ & \multicolumn{1}{c}{$\begin{array}{c}\text { Clinical } \\
\text { stage }>\mathrm{T} 2\end{array}$} & P-value \\
\hline Patient age & $69.07 \pm 7.91$ & $65.75 \pm 12.93$ & 0.315 \\
PSA & $24.63 \pm 22.78$ & $45.37 \pm 34.61$ & 0.024 \\
AR-B & $245.45 \pm 65.64$ & $305.50 \pm 15.05$ & 0.080 \\
AR-A+B & $182.78 \pm 21.38$ & $216.85 \pm 12.97$ & 0.035 \\
\hline
\end{tabular}

Dual immunofluorescent staining $A R-A$ and $-B$ expression in different prostate tissues. We illustrated that red fluorescence excited from $\mathrm{Cy} 3$ represented $\mathrm{AR}-\mathrm{A}$ and $-\mathrm{B}$, and that green fluorescence from FITC represented AR-B only. We found that the level of AR-A and -B isoform expression and the $\mathrm{AR}-\mathrm{A} / \mathrm{B}$ ratio in $\mathrm{BPH}$ had no difference compared to normal prostate $(\mathrm{P}<0.05)$. The $\mathrm{PCa}$ tissues indicated an enhanced expression of red (2.10 and 1.93-fold) and green (2.528 and 2.306-fold) fluorescence in contrast to the normal prostate tissue and BPH (Figs. 5 and 6). Red and green fluorescence were highest in the Gleason $>7$ group $(\mathrm{P}<0.05$ for all), and were elevated in the Gleason $\leq 7$ group $(\mathrm{P}<0.05$ for all $)$ in comparison to normal prostate (Table III). Red fluorescence was elevated in the clinical stage $>\mathrm{T} 2$ group $(\mathrm{P}<0.05)$, although the difference in the green fluorescence, was not statistically significant $(\mathrm{P}=0.08)$ compared to the clinical stage $\leq \mathrm{T} 2$ group, which could be due to the inadequate 


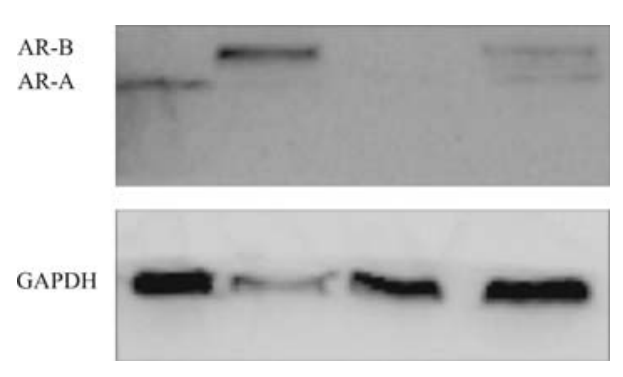

Figure 7. Transient transfection resulted in the expression of the AR-A $(87 \mathrm{kDa})$ or the AR-B (110 kDa) protein in previously AR-negative PC3 cells. Lane 1, AR-A expression in PC3 cells transfected with the pEGFPAR-A vector; lane 2, AR-B expression in $\mathrm{PC} 3$ cells transfected with the pEGFP-AR-B vector; lane 3, no AR expression in PC3s cell after transfection with the pEGFP vector; lane 4, AR-A and -B expression in LNCaP cells.

Proliferation inhibition

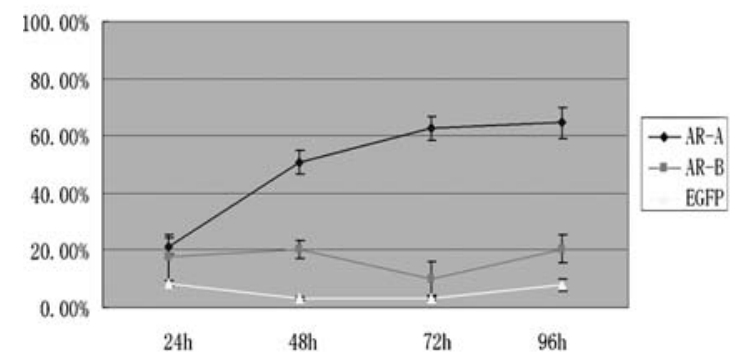

Figure 8. Effect of transient transfection with AR-A or -B on prostate cancer PC 3 cell migration.

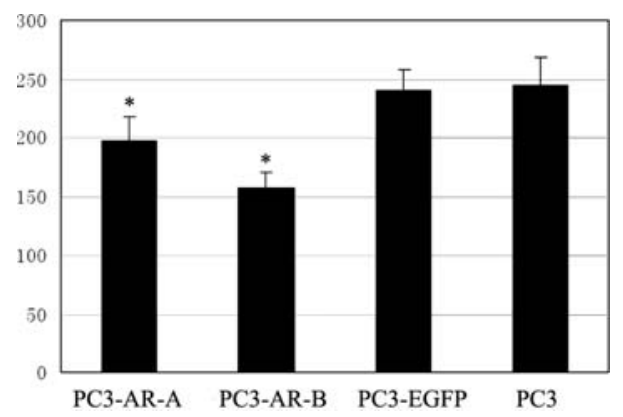

Figure 9. Effect of transient transfection with AR-A or -B on prostate cancer PC 3 cell migration. ${ }^{*} \mathrm{P}<0.05$ compared to the corresponding controls.

tissues in the clinical stage $>\mathrm{T} 2$ group (Table IV). These data were consistent with former results.

Effect of AR-A on cell proliferation and migration. Comparison of the physiological properties of AR-A and -B was possible by using 2 models of transiently transfected cell types. The PC3 cells were devoid of a functional AR and did not respond to androgen action. The expression of AR-A was achieved by the excision of a $561 \mathrm{bp}$ fragment out of pEGFPAR-B. The truncated vector lacked the DNA sequence for the first 187 amino acids including Met-1, but had retained the Met-188 translation initiation signal (Fig. 1). Transient transfection resulted in the expression of the AR-A $(87 \mathrm{kDa})$ or the AR-B (110 kDa) antigen in previously AR-negative PC3 cells (Fig. 7).

AR-defective PC3 cells were transfected with AR expression vectors, and the effects on cell proliferation mediated by the AR isoforms, were measured by CCK8. The expression of the AR-A protein significantly decreased cell proliferation by $61 \%$ on days $3-4$ of transfection $(\mathrm{P}<0.05)$ (Fig. 8). The expression of AR-B decreased cell proliferation only by $10-20 \%$. For further investigation, we compared the influence of AR-A and -B on cell migration. Fig. 7 shows that, $\mathrm{PC} 3-\mathrm{AR}-\mathrm{B}$ and $\mathrm{PC} 3-\mathrm{AR}-\mathrm{A}$ cells significantly $(\mathrm{P}<0.05$ for all) decreased migration assays in vitro compared to the PC3 control group. However, the inhibition of cell migration in PC3-AR-A was weakened compared to PC3-AR-B (Fig. 9). The cell migration ability to invade Matrigel was markedly decreased in the PC3-AR-B or PC3-AR-A clones, indicating that the decreased invasive phenotype of the AR-positive PC cells was due to the AR-A and -B expression.

\section{Discussion}

Different receptor isoforms derived from a single structural gene have been described in many members of the nuclear receptor superfamily $(16,17)$. AR isoforms were first reported in 1994 (3). Similar to PR, AR isoforms include an N-terminus truncated isoform A and a full-length isoform B. Many reports have proven that the diversity of the PR isoforms is relevant to mammary carcinomas and endometrial cancer $(8,18)$. Human AR is detectable in immunoblots as a major isoform migrating at $110 \mathrm{kDa}(\mathrm{AR}-\mathrm{B})$ and, in many tissues, as a less abundant isoform migrating at $87 \mathrm{kDa}$ (AR-A). The existence of 2 isoforms in both $\mathrm{AR}$ and $\mathrm{PR}$ suggests that the diversity of the AR isoforms could be related to PCa or other cancers. Catalano et al described a characteristic loss in the expression of AR-B in colon cancer, whereas the AR-A expression remained unchanged (9). Xia et al discovered 3 types of AR isoforms, which were detected with $\mathrm{pI}$ values at $6.5,6.0$, and 5.3 by the high resolution isoelectric focusing method (19). The expression of the AR isoforms differs in various prostate cancer tissues, which could be related to the different effects of anti-androgen therapy in PCa patients. Recently, Guo et al identified a new AR splice variant that contains the intact NTD and DBD but lacks the hinge region and LBD (11). This variant is constitutively active and is significantly up-regulated during PCa progression which could be correlated with tumor recurrence after radical prostatectomy. In the sequential study by Wilson and McPhaul, they found that the immunoreactive AR protein was present in a wide variety of human fetal and adult tissues, including adult prostate and prostate cancer (15). However, there are only 3 adult prostate tissues and 5 prostate cancer tissues, which is insufficient for statistical analysis. We collected 80 different prostate tissues to analysize the differential expression of the AR isoforms. AR is essential for gender differentiation and prostatic epithelial cell proliferation (20). It also plays a critical role in prostate cancer. Studies have shown that AR is significantly up-regulated in metastatic prostate carcinoma (21). In this study, we discovered that these 2 AR isoforms, especially the AR-A isoform, were elevated in prostate cancer. We found no statistical relation- 
ship between the expression level of $\mathrm{AR}-\mathrm{A} / \mathrm{B}$ and the patient age. However, the Gleason scores were related to the elevated expression of AR-A and -B, implicating the correlation of the $\mathrm{AR}$ isoforms elevation with malignant behavior in prostate cancer. Our results differ from the ones reported in the study on colon cancer by Catalano, et al, in that AR-B, was still the dominant $\mathrm{AR}$ protein present in all $\mathrm{PCa}$ tissues, though the AR-A/B ratio was increased (9).

The study by Gregory et al in 2001 did not show any evidence of a functional AR-A isoform (22). However, a later study demonstrated that the overexpression of AR-A reduced DHT-dependent DNA synthesis when transfected together with AR-B in AR-defective HOB and GSF-540 cells. Whether the activated AR can promote prostate cancer cell migration, still remains unknown. Certain studies have indicated that the activated AR-B can promote prostate cancer cell migration $(23,24)$, although others have shown that androgen derivatives can inhibit this phenomenon $(25,26)$. The AR signal pathway could have diverse effects on the molecules involved in the processes of invasion and metastasis which could lead to positive (the up-regulation of NEP, HSP, DPM3/prostin-1, the down-modulation of the $\alpha 6 \beta 4$ and $\alpha 3 \beta 1$ integrins, MMP1, MMP3, MMP7, and ET-1 secretion) and to negative (the upregulation of pro-MMP-2) effects on $\mathrm{PC}$ cell invasion. The loss of androgen dependence following endocrine therapy for $\mathrm{PCa}$ could thus result in the selection of cells with a higher invasive potential due to the loss of androgen regulation of some genes important for progression. In order to determine the influence of AR-A and -B on the migratory ability in prostate cancer cells, PC3 cells were transfected with pEGFPAR-A or pEGFP-AR-B. Transwell assays showed the decreased cell mobility of the pEGFP-AR-A-PC3 and pEGFP-AR-PC 3 cells. Our results demonstrated that the lower invasive phenotype of the AR-expressing PC cells is, at least in part, due to the modulation of the expression of the AR isoform. Whether AR-A could regulate the invasion of prostate cancer PC3 cells by the modulation of molecules mentioned above, needs further investigation.

There is a general consensus that the expression of AR leads the growth retardation of PC cells in vitro (27-30). In this study, we showed that AR-A depressed cell proliferation in PC3 cells much more powerfully than AR-B. Even though we showed that AR-A can function differently from AR-B, further study needs to be carried out to examine whether they could regulate a subset of the signaling pathway.

The study by Wilson and McPhaul showed that AR forms with a gel mobility similar to that of the previously described $87 \mathrm{kDa}$ AR-A, result from the in vitro proteolytic cleavage of $\mathrm{NH} 2-$ or the carboxyl-terminal regions during cell extraction and storage. However, the expression of the N-terminally truncated AR isoform in prostate tissues was not similar to that of the carboxyl-terminally truncated AR isoform. Various protease inhibitors added to the protein extraction procedure did not influence the expression of the $\mathrm{N}$-terminally truncated AR-A, which suggests that it could not result from proteolytic cleavage.

In conclusion, our study, to the best of our knowledge, is the first one showing that the AR-A/B ratio increased in prostate cancer, with a large quantity of specimen used. Given that AR-A and -B differ in expression and function, the development of new drugs targeting AR-A could potentially be effective for the treatment of $\mathrm{PCa}$.

\section{Acknowledgements}

This research was supported by the National Natural Science Foundation of China.

\section{References}

1. Griffin JE and Wilson JD: The syndromes of androgen resistance. N Engl J Med 302: 198-209, 1980.

2. Beato M: Gene regulation by steroid hormones. Cell 56: 335-344, 1989.

3. Wilson CM and McPhaul MJ: A and B forms of the androgen receptor are present in human genital skin fibroblasts. Proc Natl Acad Sci USA 91: 1234-1238, 1994.

4. Kastner P, Krust A, Turcotte B, et al: Two distinct estrogenregulated promoters generate transcripts encoding the two functionally different human progesterone receptor forms A and B. EMBO J 9: 1603-1614, 1990.

5. Wen DX, Xu YF, Mais DE, Goldman ME and McDonnel1 DP. The $\mathrm{A}$ and $\mathrm{B}$ isoforms of the human progesterone receptor operate through distinct signaling pathways within target cells. Mol Cell Biol 14: 8356-8364, 1994.

6. Vegeto E, Shahbaz MM, Wen DX, Goldman ME, O'Malley BW and McDonnell DP: Human progesterone receptor A form is a cell- and promoter-specific repressor of human progesterone receptor B function. Mol Endocrinol 7: 1244-1255, 1993

7. Shyamala G, Yang X, Silberstein G, Barcellos-Hoff MH and Dale E: Transgenic mice carrying an imbalance in the native ratio of $\mathrm{A}$ to $\mathrm{B}$ forms of progesterone receptor exhibit developmental abnormalities in mammary glands. Proc Natl Acad Sci USA 95: 696-701, 1998.

8. Graham JD, Yeates C, Balleine RL, et al: Characterization of progesterone receptor $\mathrm{A}$ and $\mathrm{B}$ expression in human breast cancer. Cancer Res 55: 5063-5068, 1995.

9. Catalano MG, Pfeffer U, Raineri M, et al: Altered expression of androgen-receptor isoforms in human colon-cancer tissues. Int J Cancer 86: 325-330, 2000

10. Liegibel UM, Sommer U, Boercsoek I, et al: Androgen receptor isoforms AR-A and AR-B display functional differences in cultured human bone cells and genital skin fibroblasts. Steroids 68: 1179-1187, 2003.

11. Guo Z, Yang X, Sun F, et al: A novel androgen receptor splice variant is up-regulated during prostate cancer progression and promotes androgen depletion-resistant growth. Cancer Res 69: 2305-2313, 2009

12. Jemal A, Siegel R, Ward E, et al: Cancer statistics, 2008. CA Cancer J Clin 58: 71-96, 2008.

13. Prostate cancer. NCCN clinical practice guidelines in oncology. J Natl Compr Cancer Netw 2: 224-248, 2004.

14. Pietrzkowski Z, Mulholland G, Gomella L, Jameson BA, Wernicke D and Baserga R: Inhibition of growth of prostatic cancer cell lines by peptide analogues of insulin-like growth factor 1. Cancer Res 53: 1102-1106, 1993.

15. Wilson CM and McPhaul MJ: A and B forms of the androgen receptor are expressed in a variety of human tissues. Mol Cell Endocrinol 120: 51-57, 1996.

16. Evans RM: The steroid and thyroid hormone receptor superfamily. Science 240: 889-895, 1988.

17. Carson-Jurica MA, Schrader WT and O'Malley BW: Steroid receptor family: structure and functions. Endocr Rev 11: 201-220, 1990.

18. Bamberger AM, Milde-Langosch K, Schulte HM and Loning T: Progesterone receptor isoforms, PR-B and PR-A, in breast cancer: correlations with clinicopathologic tumor parameters and expression of AP-1 factors. Horm Res 54: 32-37, 2000.

19. Xia SJ, Tang XD and Ma QZ: Androgen receptor isoforms in human prostatic cancer tissue and LNCaP cell line. Asian J Androl 3: 223-225, 2001.

20. Chesire DR and Isaacs WB: Beta-catenin signaling in prostate cancer: an early perspective. Endocr Relat Cancer 10: 537-560, 2003.

21. Chambers AF, Groom AC and MacDonald IC: Dissemination and growth of cancer cells in metastatic sites. Nat Rev Cancer 2: 563-572, 2002. 
22. Gregory $\mathrm{CW}, \mathrm{He} \mathrm{B}$ and Wilson EM: The putative androgen receptor-A form results from in vitro proteolysis. J Mol Endocrinol 27: 309-319, 2001.

23. Nightingale J, Chaudhary KS, Abel PD, et al: Ligand activation of the androgen receptor downregulates E-cadherin-mediated cell adhesion and promotes apoptosis of prostatic cancer cells. Neoplasia 5: 347-361, 2003.

24. Hara T, Miyazaki H, Lee A, Tran CP and Reiter RE: Androgen receptor and invasion in prostate cancer. Cancer Res 68: 1128-1135, 2008.

25. Guerini V, Sau D, Scaccianoce E, et al: The androgen derivative 5alpha-androstane-3beta,17beta-diol inhibits prostate cancer cell migration through activation of the estrogen receptor beta subtype. Cancer Res 65: 5445-5453, 2005.

26. Baek SH, Ohgi KA, Nelson CA, et al: Ligand-specific allosteric regulation of coactivator functions of androgen receptor in prostate cancer cells. Proc Natl Acad Sci USA 103: 3100-3105, 2006.
27. Heisler LE, Evangelou A, Lew AM, Trachtenberg J, Elsholtz HP and Brown TJ: Androgen-dependent cell cycle arrest and apoptotic death in PC-3 prostatic cell cultures expressing a full-length human androgen receptor. Mol Cell Endocrinol 126: 59-73, 1997.

28. Shen R, Sumitomo M, Dai J, et al: Androgen-induced growth inhibition of androgen receptor expressing androgen-independent prostate cancer cells is mediated by increased levels of neutral endopeptidase. Endocrinology 141: 1699-1704, 2000.

29. Bonaccorsi L, Carloni V, Muratori M, et al: Androgen receptor expression in prostate carcinoma cells suppresses alpha6beta4 integrin-mediated invasive phenotype. Endocrinology 141: 3172-3182, 2000

30. Cinar B, Koeneman KS, Edlund M, Prins GS, Zhau HE and Chung LW: Androgen receptor mediates the reduced tumor growth, enhanced androgen responsiveness, and selected target gene transactivation in a human prostate cancer cell line. Cancer Res 61: 7310-7317, 2001. 